\title{
Interactives and Visitor Learning
}

By: John H. Falk, Carol Scott, Lynn Dierking, Leonie Rennie, Mika Cohen-Jones

This is the pre-peer reviewed version of the following article:

Falk, J. H., Scott, C., Dierking, L., Rennie, L. and Jones, M. C. (2004), Interactives and Visitor Learning. Curator: The Museum Journal, 47: 171-198.

Which has been published in final form at

http://onlinelibrary.wiley.com/doi/10.1111/j.2151-6952.2004.tb00116.x/abstract.

***This version of the document is not the version of record. Figures and/or pictures may be missing from this format of the document. ***

\begin{abstract}
:
Interactives-computers and other multimedia components, physical manipulatives (including whole-body and tabletop activities), and simulations-occur in all types of museums. There is considerable interest in the nature of the learning that happens when visitors use interactives. Museum professionals have enlisted constructivist theory to support the notion that interactive elements are invaluable components of any exhibition experience, and are effective learning tools that enable active visitor engagement. Interactives are also seen as vital to sustaining institutional image and expanding institutional popularity.

Despite the increasing use of interactives in exhibitions and the substantial investments being made in their design and maintenance, there is a paucity of research as to whether these constructivist assumptions are supported. There is little work exploring visitors' perceptions of specific types of interactives, or the role of interactivity in the visitor experience generally. Museum staff thus have a limited ability to make informed decisions about the level and type of interactivity that might enhance exhibition experiences.

This paper describes a collaborative effort in 2001 by researchers at the Powerhouse Museum (PHM), Sydney; the Institute for Learning Innovation (the Institute), Annapolis, Maryland; and Curtin University of Technology (Curtin) and Scitech Discovery Centre (Scitech), both in Perth, Western Australia. This study investigated two aspects of interactivity: 1) visitor perceptions of interactivity in two different contexts, a museum and a science center; and 2) the types of shortand long-term learning that resulted from use of interactives in these two institutions.
\end{abstract}

Keywords: Museum Studies | Exhibits | Visitor Engagement | Interactivity

Article:

INTRODUCTION 
Over the years, visitor studies have tended to focus on one of two ends of the object-exhibition continuum. At one end, the field is rich in research and evaluation studies of full exhibitions, conducted to assess the learning outcomes and behaviors of visitors. Although many of these exhibition studies embedded investigations of specific exhibit elements within the study, only a small number of investigations have specifically focused on the learning outcomes resulting from visitor interaction with individual interactive exhibit elements. No studies that we are aware of have attempted to investigate interactives within different types of museum settings to assess the role of context in facilitating particular outcomes. At the other end of the continuum, there is a relatively small but useful series of studies that have been conducted recently on the role and impact of objects on visitor learning (Paris 2002). However, these studies have tended to focus on traditional objects and rarely have explored interactivity.

Although studies that specifically address questions of interactivity are relatively few, other studies can be cited that provide useful insights into questions about interactivity. ${ }^{1}$ Findings from these studies suggest that the public: 1 ) benefits from contact with interactives, 2) differentially selects between different types of interactive exhibits, and 3) learns from these interactions. However, in most of these studies, learning was defined narrowly as learning facts and concepts. What is lacking are studies that use broad definitions of learning, for example: learning as shifts in attitudes, values, and beliefs; aesthetic understandings; psychomotor skills, such as discovering how it feels to turn a pot or play an instrument; social/cultural dimensions such as learning about someone in your family; and process skills such as thinking critically and refining one’s learning skills, or perhaps even learning more about how to use a museum for lifelong learning.

One other substantial limitation exists in much of this previous research: Most findings are derived from exclusively short-term measures of visitor learning. There is a growing appreciation that short-term impact studies may not offer a sufficient basis on which to assess outcomes, both anticipated and unanticipated (Falk 1997; Falk and Dierking 1992, 2000; Stevenson 1991). Human minds build new understandings through a continuous process of perceiving new patterns, images and ideas and accommodating them within existing structures (Edelman 1987; Damasio 1994). Recent research suggests that memories are only partially laid down at the time of an event. The whole process of memory-building occurs over hours, days and sometimes even weeks (Nader 2003; Schacter 1999). Hence, when a museum visitor is asked to tell you what they remember immediately following their experience, what they provide is exactly that-what they remember right after the experience. Memories visitors have at that instant are unlikely to be the same as the memories they will have a few days, weeks, months or years later (Adelman, Falk, and James 2000). Several recent investigations reinforce observation that learning happens continuously, derives from many sources, and occurs in many ways (Anderson 1999; Ellenbogen 2002, 2003; Medved 1998; Luke, Dierking, Cohen Jones, and Wadman 2002). For example, Anderson (1999) found that children's understanding of electricity and magnetism was an amalgam of information gathered from school, a museum field trip, experiences at home with toys, books and television, and conversations with friends and family.

This study was designed to address some of these gaps in the research. We wanted to: 1) broadly investigate learning outcomes in interactive exhibit elements; 2) examine this interactivity in two 
different contexts (a museum and a science center); and 3) extend the time-frame of the investigation beyond the immediate museum experience. We had three research questions:

1. What do visitors bring to their museum experience generally, and their interactive experience specifically, in terms of prior knowledge and interest, agenda and perceptions?

2. What role does the context of the institution play in these perceptions?

3. What is the nature of both short-term and long-term learning outcomes resulting from visitors' experiences with interactives?

\section{METHODS}

This study was intended to provide a useful basis on which to begin a discussion about the learning that occurs as a consequence of visitors' perceptions of interactivity and their use of interactive exhibits. It was conducted at two sites: the Powerhouse Museum, which is the flagship of the Museum of Applied Arts and Sciences, and is a collections-based museum with multiple fields that include science; and Scitech, an interactive science center. To focus the study, eight interactives (four at each of the two institutions) were chosen to represent an array of types of interactive experiences (table 1.) Researchers conducted this study using a multiplemethods approach. Visitors were selected randomly and data was collected using integrated methods at three different points: 1 ) before the visitor entered the exhibition in which the interactive was located, 2) right after the experience, and 3) four to eight months after the experience. We approached visitors as they entered the museum or science center and invited them to participate in some research that would take about an hour to complete. We did not tell them what the study was about. Because of the time-commitment required, we offered visitors an incentive to participate. When a visitor was part of a family group or a set of other adults, we suggested that he/she could participate in the pre-exhibition research and then join his/her companions in the exhibition. The intent was to create as natural an experience as is possible when conducting a research study within a museum. Data was collected by a team of Institute researchers, senior PMH staff, and volunteers trained by the Institute, between January and March 2002.

Data collection before the exhibition-After agreeing to participate in the study, each participating visitor first underwent a baseline interview with researchers. He/she was asked about age, residence, formal education, prior interests and knowledge of science (but not about interest in interactives), history of visitation to the institution, and a host of other psychographic and demographic questions. To better understand visitors' prior perceptions of the institution, and the extent to which interactivity was a specific expectation or outcome of the museum or science center experience, researchers also utilized Personal Meaning Mapping or PMM (Falk 2003; Falk, Mousourri, and Coulson 1998) during pre-exhibition data collection. Visitors were asked to share their thoughts about the word "museum," in the case of Powerhouse visitors, or the word "science center" in the case of Scitech visitors. Specifically, visitors were asked, "What comes to mind when you see the word museum/science center?” 
Table 1: An overview and description of the interactives included in this study.

\begin{tabular}{|c|c|c|c|}
\hline Institution & Interactive & Description & \\
\hline \multirow[t]{4}{*}{ Powerhouse } & \multirow[t]{2}{*}{ Ecologic } & Bigfoot & $\begin{array}{l}\text { Bigfoot is a computer interactive } \\
\text { that allows visitors to determine and } \\
\text { compare the size of their "footprint" } \\
\text { on the earth by inputting informa- } \\
\text { tion about their lifestyle. }\end{array}$ \\
\hline & & Gridlock & $\begin{array}{l}\text { Gridlock allows the visitor to role } \\
\text { play being a politician trying to } \\
\text { resolve Sydney's traffic problems; } \\
\text { visitors make choices and see the } \\
\text { environmental, economic and politi- } \\
\text { cal consequences of their decisions. }\end{array}$ \\
\hline & \multirow[t]{2}{*}{ Experimentations } & Fireworks & $\begin{array}{l}\text { At Fireworks, visitors are able to } \\
\text { make several different kinds of virtu- } \\
\text { al fireworks by pressing buttons to } \\
\text { combine different chemicals. }\end{array}$ \\
\hline & & Firebrigade & $\begin{array}{l}\text { Firebrigade provides an opportunity } \\
\text { for visitors to experiment with con- } \\
\text { verting their own mechanical energy } \\
\text { into electrical energy in order to } \\
\text { make things work. }\end{array}$ \\
\hline \multirow[t]{4}{*}{ Scitech } & \multirow[t]{2}{*}{ Spin/Drive } & Driving Tired & $\begin{array}{l}\text { Driving Tired is a driving simulator } \\
\text { in which the visitor is able to role } \\
\text { play driving in a tired state, make a } \\
\text { variety of decisions, and see how } \\
\text { those decisions affect their success } \\
\text { on the road. }\end{array}$ \\
\hline & & Spin-Out & $\begin{array}{l}\text { Spin-Out is a whole-body interactive } \\
\text { that allows visitors to experiment } \\
\text { with angular momentum while they } \\
\text { spin around. }\end{array}$ \\
\hline & \multirow[t]{2}{*}{ Music/Puzzle } & Puzzle & $\begin{array}{l}\text { Puzzle allows visitors to solve a spa- } \\
\text { tial mathematical problem by manip- } \\
\text { ulating tangram puzzle pieces in } \\
\text { order to match given shapes. }\end{array}$ \\
\hline & & Thongophone & $\begin{array}{l}\text { At Thongophone visitors can make } \\
\text { music and explore the physics of } \\
\text { sound by experimenting with hitting } \\
\text { a series of pipes of different lengths } \\
\text { with a rubber thong. }\end{array}$ \\
\hline
\end{tabular}

Visitors were then randomly assigned to visit a specific exhibition. They were instructed to view and interact with the whole exhibition, and in the course of their stay to use two interactives that were pointed out to them. They were not told how to use the interactives specifically, nor was the word "interactive" ever used, unless they themselves said it. The subjects were unobtrusively observed to gauge how they used the exhibition and the target interactives. A visitor who was part of a family or with other adults was encouraged to join the group in the exhibition so as to create as natural an experience as possible.

Data collection immediately after- Upon exiting the exhibition, visitors participated in an open-ended interview (see appendix A). They were asked to describe their experience, and in some cases-based on observations of their interaction-were also asked specific questions, 
such as: "I noticed you and your son discussing the exhibit; can you tell me what you were taking about?” They were asked to describe what they had discovered or learned from their experience.

Visitors were then asked to take another look at their Personal Meaning Maps and to add, subtract, or otherwise modify any thoughts they had previously expressed. Researchers were particularly interested in determining the degree to which interactivity emerged as an educational strategy in visitors' conceptualizations of the terms "museum" or "science center" immediately after the visit, compared to their use of the terms before entering the exhibition. Finally, visitors were asked to volunteer contact details in the event that we might wish to talk to them at a later date. Specifics about the nature of a potential follow-up interview were not given, nor was there any indication that those who volunteered would definitely be contacted.

Data collection four to eight months later-Follow-up phone interviews were conducted by researchers at PHM and Scitech four to eight months after the visitors' experiences in the institution. The purpose of the follow-up telephone interviews was to elicit in-depth, rich, and detailed qualitative and quantitative information to enhance understandings of the long-term impact of interactive experiences on visitors to free-choice learning institutions (See appendix B for the interview protocol).

The telephone interviews were designed to be conversational and to build on the substantial amount of information that had been collected from each individual during earlier in-museum interviews. The interviewer reminded the visitor of the PMM, and prompted recollections by using some words the person had previously used to describe a museum or science center. The interviewer then asked what comes to mind now when hearing the word "museum" or "science center." This approach allowed data collectors to tailor each interview to flow naturally from prior responses and the terminology that people had previously used when answering similar questions. It was also designed to allay any sense that this was a test, since we willingly provided them with the "answers" they had already given. Our interest was in ascertaining whether there were changes, if any, to these earlier responses. During the interviews, data collectors took comprehensive notes, making every effort to accurately capture visitors' exact words and ideas. A total of 80 follow-up interviews were conducted.

Data Analysis - Data was analyzed qualitatively and quantitatively. Quantitative data analysis included the use of single (Spearman's rho) and multiple regression analyses and summary statistics for central tendency (mean, mode and median). The analysis sought to determine the impact of experiencing the different types of interactives or the effects of independent variables such as the role of social group and/or prior interests and knowledge on the impact of the interaction. Since visitor learning was an important issue, visitor responses to the open-ended interviews were quantified and developed for use as dependent learning measures. These measures were then analyzed as a function of independent measures, including, but not limited to, prior experiences and expectations, and utilization of specific interactives.

Data was also analyzed qualitatively using content analysis (Bernard and Ryan 1998). Content analysis allowed researchers to systematically identify, code, and categorize primary patterns or themes within participants' responses and facilitated recognition of rich and complex patterns 
across cases. This analysis did not allow researchers to assess the relative frequency of the patterns among individual visitors, only their weight in broad strokes.

\section{RESULTS AND DISCUSSION}

A total of 199 adult visitors (99 at PHM and 100 at Scitech) participated in the study. The only selection criteria were that the sample should include adults across age cohorts and relatively equal numbers of males and females. No visitors were interviewed who were part of a school group (table 2). The response rate was 67 percent at the Powerhouse and 85 percent at Scitech.

Table 2: Characteristics of participants in the study sample.

\begin{tabular}{|c|c|c|}
\hline \multirow[t]{2}{*}{ Demographic } & \multicolumn{2}{|c|}{$\begin{array}{l}\text { Interviews with visitors (pre and post exhibition) } \\
\text { (Percents indicate \% of total responses to an item) }\end{array}$} \\
\hline & $\begin{array}{l}\text { Science center } \\
\quad(\mathrm{n}=100)\end{array}$ & $\begin{array}{l}\text { Museum } \\
(\mathrm{n}=99)\end{array}$ \\
\hline \multicolumn{3}{|l|}{ Gender } \\
\hline Male & $48 \%$ & $52 \%$ \\
\hline Female & $56 \%$ & $44 \%$ \\
\hline \multicolumn{3}{|l|}{ Age } \\
\hline $16-19$ & $5 \%$ & $2 \%$ \\
\hline $20-24$ & $10 \%$ & $18 \%$ \\
\hline $25-29$ & $8 \%$ & $18 \%$ \\
\hline $30-34$ & $20 \%$ & $20 \%$ \\
\hline $35-39$ & $20 \%$ & $8 \%$ \\
\hline $40-44$ & $14 \%$ & $5 \%$ \\
\hline $45-49$ & $11 \%$ & $4 \%$ \\
\hline $50-54$ & $0 \%$ & $11 \%$ \\
\hline $55-59$ & $6 \%$ & $9 \%$ \\
\hline $60-64$ & $5 \%$ & $1 \%$ \\
\hline $65+$ & $1 \%$ & $4 \%$ \\
\hline \multicolumn{3}{|l|}{ Education } \\
\hline Primary school & $2 \%$ & $7 \%$ \\
\hline High school & $29 \%$ & $22 \%$ \\
\hline TAFE or business college & $22 \%$ & $16 \%$ \\
\hline University degree & $32 \%$ & $34 \%$ \\
\hline Postgraduate & $15 \%$ & $21 \%$ \\
\hline \multicolumn{3}{|l|}{ Social group } \\
\hline Alone & $2 \%$ & $13 \%$ \\
\hline With spouse/partner & $6 \%$ & $42 \%$ \\
\hline With family & $87 \%$ & $26 \%$ \\
\hline With friends & $5 \%$ & $19 \%$ \\
\hline \multicolumn{3}{|l|}{ Presence of children } \\
\hline Yes & $86 \%$ & $18 \%$ \\
\hline No & $14 \%$ & $82 \%$ \\
\hline \multicolumn{3}{|l|}{ Museum visitation } \\
\hline A frequent visitor & $26 \%$ & $17 \%$ \\
\hline An occasional visitor & $27 \%$ & $57 \%$ \\
\hline Rarely visit & $34 \%$ & $26 \%$ \\
\hline First museum visit & $13 \%$ & $0 \%$ \\
\hline \multicolumn{3}{|l|}{ Visitation } \\
\hline First time & $24 \%$ & $36 \%$ \\
\hline Been before & $76 \%$ & $64 \%$ \\
\hline
\end{tabular}


Visitors in the two institutions were similar across most demographic categories, although a key area of difference in the two samples was social group. Eighty-six percent of visitors to Scitech came with children under age 12; only 18 percent of PHM visitors interviewed were accompanied by younger children, and many of the intergenerational groups visiting PHM included adolescent or adult children. (Since the $n$ for both sites was approximately 100 individuals, percentages and responses were typically identical; only percentages will be reported, unless sample sizes deviated from this norm.)

Question 1-What do visitors bring to their museum experience generally, and their interactive experience specifically, in terms of prior knowledge and interest, their agenda and perceptions?

Previous studies designed to understand visitors' perceptions of interactivity have relied on investigator-imposed criteria, for instance: "Do you find these experiences: a) fun; b) frustrating; c) educational?” Or they imposed outcomes, for instance: “Tell me what you learned about $X$.” In this study, data was collected in such a way that visitors used their own criteria and words when discussing their perceptions about the role that interactive experiences play in their learning — specifically, the role that interactivity plays in their experience at a museum/science center.

In general, three distinct roles emerged as important to these visitors:

- They promote talking, communication, or doing things together.

- They provide personal feedback.

- They encourage "learning by doing” or involve an opportunity to apply content knowledge to everyday life.

Both museum and science center visitors also talked about education and learning. Comments by visitors indicate that they are overwhelmingly interested in interactivity and frequently view interactive experiences as the best way to learn. Here are some examples:

[Interactives make the experience] intriguing, puzzling, wonderfully simple; they capture the imagination in intriguing ways, raise curiosity, and make it so easy to get that ah-ha experience when you see how it works.

Interactive exhibitions make it so museums are now more involving and engaging, particularly

for kids.

[Interactives] are a pretty interesting way for kids or for anyone to learn about new things.

Interactives grab your attention. You can learn more from doing than [you] can from just reading.

Question 2-What role does the context of the institution play in perceptions of interactivity? How did interactive experiences change those perceptions? 
Personal Meaning Maps created by visitors in the PHM were significantly different from those developed by visitors to Scitech. A bit of context is necessary here: PHM collections include the fields of design, decorative arts, transport, technology, social history and science. The diverse nature of the collection attracts visitors with a range of interests and expectations. This is different from a science center, which - by virtue of its name and content-attracts visitors with a more specific focus and expectations. The difference could potentially be a factor in the differing characteristics of the maps. Visitor maps suggested that interactivity is a major expectation of science center audiences (particularly families with young children), but is expected to play a lesser role in a museum like PHM.

Scitech visitors focused on the notion of the science center as a fun or entertaining place, more so than visitors to the Powerhouse Museum (science center: 35 percent; museum: 14 percent). Science center visitors also mentioned that children under the age of 12 years were part of the visiting audience much more frequently than museum-goers (science center: 48 percent; museum: 14 percent). Families at Scitech who were prompted to share their perceptions of a science center tended to talk explicitly about strategies for a visit more frequently than families who visited (and were prompted about) the museum. Thirty-eight percent of the science center visitors discussed various museum strategies and agendas, including: coming with the family to learn; the hands-on nature of these settings; coming often because things always change; and coming for social or leisure activity. In contrast, only 18 percent of museum visitors mentioned these types of strategies and museum agendas.

Museum visitors tended to associate the word "museum” with "knowledge," "learning," "information," "treasures," "old stuff” (museum: 46 percent; science center: two percent), "the past," "history” and "heritage.” Museum visitors also strongly associated museums with collections. For example, 88 percent of museum visitors discussed collections: archives, the display of collections, and the presence of unique objects. Only 11 percent of the science center visitors mentioned collections or objects, mostly referring to the fact that "you get to see things you don’t normally get to see.”

Experiences with interactives in museums significantly changed visitor perceptions of museums. When asked whether they would change any of the associations they had provided in the preinterview, the PHM visitors inevitably added comments and concepts related to interactivity: 19 percent of visitors mentioned interactivity during the pre-PMM, 77 percent in the post-PMM. The post-interviews revealed that the interactive experience had changed perceptions of the museum from "dry and dusty" to a place that was "modern," explored "current issues" and "looked forward." One person stated that "I wouldn't expect to see an exhibition like this one on this theme [sustainability] in a museum.” Moreover, post-exhibit interviews indicated that people had adjusted their perceptions of the type of experiences one could have in a museum to "active, fun learning instead of passive learning," where you were "able to create something yourself that's challenging" and which is about "more than history." These changes in perceptions were also observed in the long-term interviews, indicating that these changed perceptions had persisted four to eight months. 
These effects were far more obvious among museum visitors than they were for science center visitors, where the few changes observed were subtle and nuanced. This was probably due to the expectation of interactivity and hands-on engagement that already existed among science center visitors prior to the visit.

Question 3-What is the nature of both short-term and long-term learning outcomes resulting from visitors' experiences with interactives?

Visitors self-reported that they derived a variety of benefits from their interactions with exhibits. From this data, researchers compiled a list of possible learning impacts associated with various types of interactives. Unanticipated learning outcomes, as well as those outcomes planned as part of the interactive design, were considered. Seven primary findings regarding the nature of learning from interactives emerged from these data.

Finding 1-Four major categories of learning outcomes resulted from visitor interaction with the various interactive exhibits.

A major goal of this study was to define learning more broadly and investigate the outcomes that visitors themselves considered important after experiences with interactives. Eight learning dimensions and types of outcomes initially emerged from the data in this study: Knowledge, skills, interests, values, museum literacy, social learning, creativity, and awareness. Based on earlier studies (Luke, Dierking, and Falk 2001), which had indicated that the eight dimensions were not independent of one another, the eight learning dimensions were collapsed into four semi-independent categories: knowledge and skills; perspective and awareness; motivations and interests; and social learning (table 3). These four learning dimensions have been validated in other studies, and are not necessarily unique to experiences with interactive exhibits (Luke, Dierking, and Falk 2001; Luke, Dierking, Cohen Jones, and Wadman 2002).

These findings demonstrate that interactives can indeed support the learning and/or reinforcement of facts and concepts: "The faster you cycled, the more energy you created and the more lights you could turn on" (Firebrigade). They can provide opportunities for a variety of skills: "I found that with a little practice, I could begin to make reasonable music on the thing" (Thongophone). However, an important finding in this study is that other things were equally important. These included learning that results in new perspectives and awareness: "[I now know] changes I could make for the future" (Bigfoot). Also learning that develops motivations and interests: "The visual stimulation in the exhibition as a whole was fantastic - it [made me want] to gather more information” (Fireworks). And social learning: "I never realized how much my dad knew about issues related to transportation” (Gridlock). These are all dimensions of learning; the latter of these are dimensions we typically do not think and/or choose to measure. 
Table 3: Examples adults used to explain learning at interactives.

\begin{tabular}{ll}
\hline Learning outcomes & Examples of learning in these areas \\
\hline Knowledge and Skills & "Found out that perfumes were made of those bases." \\
[Fireworks] & "Learned how a generator worked." [Firebrigade] \\
& "It improved my critical thinking skills." [Gridlock] \\
"It got people thinking a bit, using lateral thinking and not & necessarily just the obvious way to go." [Puzzle] \\
& "I got better at it the longer I did it." [Thongophone] \\
\hline "It was surprising and mind-blowing and opened my mind \\
to what is happening; we thought we were doing well until \\
[we] realized there is much more to be done." [Bigfoot] \\
"I now feel very conscious of speed and danger." [Driving \\
Tired] \\
"It inspired thinking about how fireworks were made." \\
[Fireworks] \\
"In Spin-Out you get the aesthetic 'whee' movement, so \\
I'm more curious about angular momentum but still have \\
questions about it." [Spin-Out] \\
"I got interested in magnetism." [Firebrigade] \\
"My son couldn't feel the speed difference until I asked \\
him to close his eyes. We were learning from each other, \\
and I will continue to discuss it with my son." [Driving \\
Tired] \\
"It was a great way to make me and my children aware. It \\
was fun. I had more fun with my grandchild." [Firebri- \\
gade] \\
"I realized that my five-year-old was not ready for it." \\
[Puzzle] \\
\hline Social Learning
\end{tabular}

Finding 2-More than one short-term learning outcome is possible and probable from interacting with an interactive.

Short-term outcomes documented during this study support the hypothesis that learning is an individual, idiosyncratic event, and that no two people ever learn exactly the same thing in the same way from the same experience. As evidence of this conclusion, the learning results for each interactive fell into more than one of the learning dimensions. In fact, most of the interactives investigated gave all learning outcomes for at least some of the visitors (table 4). In only three cases were the four outcomes not experienced by at least one visitor in the short term. (In those cases, interaction with the Driving Tired interactive did not result in the motivation and interest outcome, and interaction with the Puzzle and Spin-Out interactives did not result in the perspective and awareness outcome.) 
Table 4: Frequency of short-term learning outcomes across interactives.

\begin{tabular}{lllll}
\hline & $\begin{array}{l}\text { Knowledge } \\
\text { and Skills }\end{array}$ & $\begin{array}{l}\text { Motivation } \\
\text { and Interests }\end{array}$ & $\begin{array}{l}\text { Perspective } \\
\text { and Awareness }\end{array}$ & $\begin{array}{l}\text { Social } \\
\text { Learning }\end{array}$ \\
\hline $\begin{array}{l}\text { Powerhouse } \\
\text { Fireworks }\end{array}$ & $73 \%(\mathrm{n}=16)$ & $27 \%(\mathrm{n}=6)$ & $14 \%(\mathrm{n}=3)$ & $5 \%(\mathrm{n}=1)$ \\
$\begin{array}{l}\text { Firebrigade } \\
\text { Gridlock }\end{array}$ & $74 \%(\mathrm{n}=14)$ & $26 \%(\mathrm{n}=5)$ & $26 \%(\mathrm{n}=5)$ & $11 \%(\mathrm{n}=2)$ \\
$\quad$ Bigfoot & $42 \%(\mathrm{n}=11)$ & $4 \%(\mathrm{n}=1)$ & $65 \%(\mathrm{n}=17)$ & $15 \%(\mathrm{n}=4)$ \\
\hline $\begin{array}{l}\text { Scitech } \\
\text { Thongophone }\end{array}$ & $78 \%(\mathrm{n}=14)$ & $17 \%(\mathrm{n}=3)$ & $17 \%(\mathrm{n}=3)$ & $11 \%(\mathrm{n}=2)$ \\
$\quad \begin{array}{l}\text { Puzzle } \\
\text { Spin-Out }\end{array}$ & $69 \%(\mathrm{n}=11)$ & $19 \%(\mathrm{n}=3)$ & $0 \%(\mathrm{n}=0)$ & $19 \%(\mathrm{n}=3)$ \\
$\quad 50(\mathrm{n}=10)$ & $24 \%(\mathrm{n}=4)$ & $0 \%(\mathrm{n}=0)$ & $18 \%(\mathrm{n}=3)$ \\
Driving Tired & $19 \%(\mathrm{n}=5)$ & $0 \%(\mathrm{n}=0)$ & $73 \%(\mathrm{n}=19)$ & $19 \%(\mathrm{n}=5)$ \\
\hline
\end{tabular}

Finding 3-Although idiosyncratic, the frequency of types of short-term learning outcomes varied in patterned ways across types of interactives.

Although interaction with each interactive resulted in multiple outcomes, the frequency of outcomes varied in patterned ways across interactives and was not affected by the type of institution within which the interactive was encountered. Knowledge and skills was the most frequent short-term outcome in five of the interactives (Fireworks, Firebrigade, Thongophone, Puzzle, and Spin-Out). Perception and awareness was the most frequent outcome in three of the interactives, all computer-based (Gridlock, Bigfoot, and Driving Tired). The social learning outcome ranked low across all of the interactives.

Finding 4-An individual visitor may derive multiple short-term outcomes from the same interactive.

Data collected during this pilot study suggests that not only were multiple outcomes possible from one interactive, but that each individual was likely to derive multiple outcomes from a single experience with one interactive. The four learning outcomes across the eight possible interactives were collapsed into a single outcome variable. For any individual, the score on this variable ("sum possible") could range from 0 (no learning reported) to 8 (all four learning outcomes for each of the two interactives with which they engaged). The range was from 0-5 across all respondents. The mean was 1.27 learning outcomes reported (table 5).

In each of the eight exhibits investigated, a majority of users described only a single outcome from using the interactive. In one exhibit only (Spin-Out), all visitors reported only a single outcome. The highest number of visitors reporting multiple outcomes occurred at Bigfoot; nearly half (45 percent) of visitors reported more than one learning outcome after using this interactive. 
Table 5: Multiple (short-term) outcomes derived by individuals across interactives.

\begin{tabular}{lll}
\hline Interactives & $\begin{array}{l}\text { Number of individuals } \\
\text { reporting a single outcome }\end{array}$ & $\begin{array}{l}\text { Number of individuals } \\
\text { reporting multiple outcomes }\end{array}$ \\
\hline $\begin{array}{l}\text { Powerhouse } \\
\text { Fireworks }\end{array}$ & $82 \%(\mathrm{n}=18)$ & $18 \%(\mathrm{n}=4)$ \\
Firebrigade & $68 \%(\mathrm{n}=13)$ & $32 \%(\mathrm{n}=6)$ \\
Gridlock & $77 \%(\mathrm{n}=20)$ & $23 \%(\mathrm{n}=6)$ \\
Bigfoot & $55 \%(\mathrm{n}=23)$ & $45 \%(\mathrm{n}=19)$ \\
\hline Scitech & & \\
Thongophone & $78 \%(\mathrm{n}=14)$ & $22 \%(\mathrm{n}=4)$ \\
Puzzle & $94 \%(\mathrm{n}=15)$ & $6 \%(\mathrm{n}=1)$ \\
Spin-Out & $100 \%(\mathrm{n}=17)$ & $0 \%(\mathrm{n}=0)$ \\
Driving Tired & $88 \%(\mathrm{n}=23)$ & $12 \%(\mathrm{n}=3)$ \\
\hline
\end{tabular}

Finding 5-Visitors arrive with perceptions, expectations, prior interests and knowledge that influence the learning that results from interactive exhibit elements.

Learning is rarely linear and is strongly influenced by an individual's perceptions, interests and motivations, and by prior experiences - the unique learning preferences, capacities and styles of the learner (Falk and Dierking 1992, 2000). For the purposes of this study, researchers explored a whole range of variables that might have correlated with visitor outcomes. A wide range of independent variables emerged as potentially important co-variates to learning from interactives. These included: the age and gender of the visitor; the presence of children; prior knowledge and interest; prior visits to this and other similar institutions; and expectations for learning and perceptions of the learning that happens in museums and science centers.

We used quantitative methods to determine the relative role and importance of all these visitor entry variables. Using the collapsed outcome variable that was created from the sum of all possible outcomes as a dependent measure, we conducted a single load regression analysis of the various independent measures. Results suggested a statistically significant but weak relationship $(p=.001)$ between the outcomes visitors derived from their experiences and the predictors of age, gender, visitor type (frequency of visitation to museums in general), social group, prior visit, institution, and presence of children in the social group. The overall variance explained by these variables (the adjusted $R 2$ ) was slightly less than 10 percent $(R 2=.097)$. Although the total variance explained was low, people's individual profiles captured 60.7 percent of this variance. In other words, these variables are collectively important in explaining the variance of learning outcomes from interactives, but in and of themselves, no one of these variables is capable of predicting learning outcomes in and of themselves.

We were also intent on exploring the relationship between visitor outcomes and a visitor's prior knowledge of and interest in science. Quantitative analysis suggests a very strong relationship ( $r$ $=.602$ ) between knowledge about science and interest in science. Although individuals attending Scitech reported significantly higher knowledge levels than their PHM counterparts ("institution 
attended" explained 28.5 percent of the variance in people's self-reported scores), prior knowledge and interests in science were not predictive of the specific impacts visitors derived from their experience.

Finally, although the relationship between categories of short-term outcomes (the four learning dimensions) and visitors' perceptions (per-exhibition PMM) did not seem to be statistically correlated to one another, a more fine-grained qualitative analysis revealed clear relationships in some cases. In order to highlight the role of people's prior perceptions of the institution (and specifically the learning that occurs there) in influencing visitor learning, researchers conducted a focused analysis of a sub-set of visitors to the Powerhouse Museum. The analysis suggested that visitors' specific expectations for what they will learn and do in the museum or science center did in many cases directly relate, in predictable ways, with the outcomes they derived from their experiences. The following examples from visitors to the Powerhouse Museum illustrate this general trend:

[Pre-exhibition PMM]: This is a place to think about history and the future. People can learn what has happened in the past and then can learn how to change the future. That's very important.

[Outcome]: The exhibit provided information on the big issue, but no one ever told me what was going to happen, or when. I did learn that it takes 30 years for the effect of banning CFCs to take effect. Thus by 2010 ...

[Pre-exhibition PMM]: This is a place for education for the children, enjoyment, great fun.

[Outcome]: My daughter tried doing it; it did not work. It was great fun, though. Lots of fun.

[Pre-exhibition PMM]: It is a place to get information. Learning about concepts you don't really know about.

[Outcome]: I learned that I had a misconception about physics.

Finding 6-Short-term learning outcomes are not predictive of long-term learning outcomes.

Of the original study population, roughly 70 percent (140 visitors) agreed to provide us with recontact information and actually provided us with sufficient (complete and accurate) and reasonable (Australian residence) information so they could be telephoned at a later date. An effort was made to re-contact as many of these 140 visitors as was possible after a reasonable time frame (within four to eight months). A total of 80 of these individuals (57 percent) were successfully interviewed (47 PHM and 33 Scitech). These 80 individuals were demographically comparable to the larger pool of 199 visitors included within the first part of the study. They were comparable as a function of gender: equal numbers of males and females (male: 50 percent, $\mathrm{n}=40$; female: 50 percent, $\mathrm{n}=40$ ). They were comparable in age: visitors in the sub-sample represented all age ranges, with the same average age, 35-39 years, as the larger sample. They 
were comparable in frequency of museum visitation (47 percent were occasional visitors). Other than our ability to make re-contact (which we had no reason to believe was based upon attributes related to visitor learning), there was no obvious bias in how we determined who should be recontacted, and little or no difference in the demographic or psychographic attributes of the recontacted population. Thus we concluded that, for the purposes of this exploratory study, the findings from this sub-sample of visitors could be reasonably generalized to the larger sample.

Table 6: Frequency of long-term learning outcomes across interactives.

\begin{tabular}{|c|c|c|c|c|}
\hline & $\begin{array}{l}\text { Knowledge } \\
\text { and Skills }\end{array}$ & $\begin{array}{l}\text { Motivation } \\
\text { and Interests }\end{array}$ & $\begin{array}{l}\text { Perspective } \\
\text { and Awareness }\end{array}$ & $\begin{array}{l}\text { Social } \\
\text { Learning }\end{array}$ \\
\hline \multicolumn{5}{|l|}{ Powerhouse } \\
\hline Fireworks & $67 \%(\mathrm{n}=8)$ & $25 \%(\mathrm{n}=3)$ & $50 \%(\mathrm{n}=6)$ & $8 \%(\mathrm{n}=1)$ \\
\hline Firebrigade & $58 \%(\mathrm{n}=7)$ & $8 \%(\mathrm{n}=1)$ & $42 \%(n=5)$ & $17 \%(\mathrm{n}=2)$ \\
\hline Gridlock & $8 \%(n=1)$ & $25 \%(\mathrm{n}=3)$ & $50 \%(\mathrm{n}=12)$ & $8 \%(\mathrm{n}=1)$ \\
\hline Bigfoot & $29 \%(n=6)$ & $5 \%(\mathrm{n}=1)$ & $100 \%(\mathrm{n}=21)$ & $5 \%(n=1)$ \\
\hline \multicolumn{5}{|l|}{ Scitech } \\
\hline Thongophone & $29 \%(n=4)$ & $21 \%(\mathrm{n}=3)$ & $79 \%(\mathrm{n}=11)$ & $43 \%(n=6)$ \\
\hline Puzzle & $80 \%(\mathrm{n}=8)$ & $10 \%(\mathrm{n}=1)$ & $40 \%(n=4)$ & $60 \%(\mathrm{n}=6)$ \\
\hline Spin-Out & $41 \%(\mathrm{n}=7)$ & $12 \%(\mathrm{n}=2)$ & $41 \%(\mathrm{n}=7)$ & $35 \%(n=6)$ \\
\hline Driving Tired & $10 \%(\mathrm{n}=1)$ & $10 \%(\mathrm{n}=1)$ & $70 \%(\mathrm{n}=7)$ & $40 \%(n=4)$ \\
\hline
\end{tabular}

As part of the follow-up interview, individuals were administered another round of personal meaning mapping (as described earlier) as well as a series of open-ended questions comparable to those used in the original in-museum post-experience interviews. PMM responses were very similar to those given while in the museum/science center, but individual self-reports of outcomes varied considerably from our previous data (table 6).

Sixty percent of all of the long-term outcomes (across visitors and across interactives) can be lumped into the perspective and awareness learning dimension (a dimension consistently high across all interactives). This compares to 40 percent of the outcomes in the knowledge and skills dimension, 27 percent in social learning, and 14 percent of the outcomes associated with motivation and interests. Although this is still a small category, visitors were much more likely in the long term than in the short term to indicate social outcomes as one of their learning outcomes.

A quantitative analysis of open-ended responses by visitors revealed only limited correlations between short-term and long-term reported outcomes. This suggests that even when individuals reported that they had benefited from use of an interactive by increases or changes in their knowledge, skills, or interests immediately after their visit, the perception of those salient outcomes did not necessarily persist over time. This finding reinforces the importance of thinking broadly about learning outcomes when assessing the impact of museum experiences, and of extending the time frame of measurement if one wants to document meaningful long-term visitor learning. 
The following comments reveal the types of outcomes visitors self-reported, short and long-term:

[Immediate outcome]: I found out it would take five earths to sustain the world's population if everyone was like me.

[Several months later]: I am more conscious of recycling and have started separating my rubbish. I recognize that I am a water abuser, even simple things like keeping the tap water running while brushing your teeth wastes water.

[Immediate outcome]: Fun and amazing.

[Several months later]: I realized that immature drivers did quite poorly on Driving Tired. I've since played computer games involving driving with my son ... we played these games at home.

[Immediate outcome]: Driving Tired was frightening, the realization of how little time you have, but it shows you that you need to think about it.

[Several months later]: I spoke to my daughter and grandson after that. We've had many casual conversations about it.

Finding 7-The most persistent learning outcome over time was a positive shift in visitors' perspective and awareness.

In addition to displaying little relationship to short-term outcomes, long- term data suggests at least two additional trends. First, in 27 percent of the cases, no long-term outcomes were reported from a visitor's experiences at interactives. This result was not restricted to any one particular interactive in the study, but occurred at least once for all eight of the interactives investigated. This finding reinforces the observation that a one-time, ephemeral experience at an interactive does not necessarily result in permanent learning, no matter how good the interactive.

Second, preliminary findings suggest that a large majority (73 percent) of visitors could articulate outcomes for at least one of their experiences, even after several months of elapsed time. The majority of these visitors self-reported that they gained new perspectives and awareness. The following comments (from visitors who experienced the Puzzle and Thongophone interactives at Scitech) are indicative of the broad range of perspective-andawareness comments that visitors shared several months after their experience:

The Puzzle got me thinking differently about interpretation. Now, at work and with my husband, I am always conscious of interpretation: "Is this what my boss wants or is this what I think they mean?”

I never knew about different-sized pipes making different noises. I've since seen bottles filled with water to different levels and thought back to Thongophone.

I realized that pipes are usually used for water but can be used for music. [Thongophone] 


\section{CONCLUSIONS}

This research presents findings about the nature of visitors' interactions with specific interactives in science centers and museums, and the role interactivity plays in visitor experiences in general. Findings from this study can be used as a foundation for discussing the role that interactive exhibits play in facilitating a range of visitor learning outcomes.

This study also points out the methodological challenges of attempting such investigations in free-choice learning settings such as museums and science centers. Ethical and practical considerations necessitated that we approach people and ask their permission to participate in the study. The time commitment expected of visitors required that we provide an incentive. We randomly assigned participants to visit a particular exhibition and set of interactives and we asked for contact information so that we could follow up with a sub-sample of these visitors four to eight months later.

The study confirms that the public understands and values the interactive nature of such settings, which people usually speak of as "hands-on." Often, people are actively seeking out interactivity by visiting these settings. This was particularly the case for visitors to science centers. The public perceives that interactive exhibits afford opportunities to promote talking, communication, and doing things together; to receive personal feedback; to engage in "learning by doing"; and to apply content knowledge to everyday life. All these things are what they associate with quality out-of-school learning. There was a strong indication that these perceptions influenced not only visitors' ideas of what they could do at a museum or science center, but also the benefits they derived from the experience. In other words, there was a strong suggestion that these expectations became self-fulfilling prophesies: Visitors who perceived interactivity as an essential component of their learning were able to report significant educational benefits and diverse learning outcomes from their interactions with them, both short-term and long-term.

Visitor PMMs suggest that interactivity is a major expectation of science center audiences (particularly families with young children), but is less expected in a museum like PHM, despite efforts that museums have made in the last decade to be more engaging and interactive. Interestingly, though, experiences with interactives in the PHM significantly changed visitor perception of museums. These changes in perception were observed in both the short- and the long-term interviews-indicating that these changed perceptions were likely to be real changes, since they persisted four to eight months after the original experience. These findings are encouraging — suggesting that, as visitors have more interactive experiences in museums, their perceptions of these places as "old” and "dusty" can change. Such changes in perceptions were not evidenced by science center visitors; in those cases, the few changes in perceptions observed after engagement with interactives were subtle and nuanced, probably because science center visitors expect interactivity and hands-on engagement.

In terms of the learning component of this study, there were many interesting findings, but three aspects stand out for us as important to investigate further. The first key finding was that more than one type of learning outcome resulted from each of the eight different types of interactives investigated (though not all learning outcomes were equally likely to be observed for each 
interactive). Many commentators have suggested that museums support and facilitate multiple learning outcomes (Falk and Dierking 2000; Ansbacher 2003; Leinhardt, Crowley, and Knutson 2002). This investigation, and the previously cited study conducted at the Children's Museum, Indianapolis (Luke, Dierking, and Falk 2001), document the diversity of possible learning outcomes and provide some initial descriptive categories for classifying such outcomes. It is not a surprising finding that individual exhibit elements elicit multiple outcomes, but it is useful to have empirical data that supports that assumption. Similarly, it makes sense that visitors should derive multiple outcomes from their experiences, even at an individual interactive exhibit element; but documentation of this assumption is still valuable.

The data from this study also reinforce the currently accepted notions that visitors enter the museum with pre-existing knowledge, experience, interest, motivation and established social/cultural relationships, and that these pre-existing conditions strongly influence their inmuseum learning. Although the individual effects were not large, all of the above mentioned variables were shown to influence, at least to some degree, the nature and extent of visitor learning in these exhibits. More surprising, though, were the differences in visitors' short- and long-term learning outcomes.

The final major finding from this investigation relates to changes in individuals' self-reported learning outcomes. When visitors were interviewed in the museum immediately following their visit, they overwhelmingly reported that changes in knowledge and skills were the primary type of learning they experienced from engagement with the interactive. The three computer interactives in the sample (Gridlock, Bigfoot, and Driving Tired) all also seemed to facilitate changes in visitors' perspectives and awareness. In the museum, changes in interest and motivation were also cited by a small but significant number of visitors as important outcomes of their experience with interactives. Relatively few visitors (with the exceptions noted above) described changes in the other two learning outcome categories-perspective and social learning. This finding might be satisfying to exhibit designers and might fulfill the expectations of many museum professionals, since these exhibits were designed explicitly to facilitate changes in visitors' knowledge and skills and to stimulate visitor interest and motivation. However, visitor self-reported learning over time provided a different picture.

After four to eight months, visitors described predominantly perspective-and-awareness learning outcomes. Only a few visitors described outcomes in the knowledge-and- skills domain, and then only for selected interactives. The interest-and-motivation category was also less frequently cited. And although very few visitors described social learning as a result of their exhibit experience in the short term, several months later social learning emerged as a common outcome.

Few of us would question that perspective-and-awareness and social learning are important and legitimate consequences of a museum visit, but they are not the learning outcomes most museum professionals - particularly science museum professionals - typically cite as their major educational goals for visitors. These findings do not allow us to determine whether there is a lack of reinforcement for short-term learning in the knowledge- and-skills domain (causing these types of learning to be extinguished, or to become of secondary importance to visitors). Similarly, we don't know whether short-term learning is converted eventually into changes in 
perspective and awareness. Any or all of these findings give pause for thought and suggest the importance of further investigation.

These findings raise another issue. Although sample sizes are low, the data from this study warns us against generalizing about long-term learning based on short-term questioning of visitors. What visitors said as they exited the museum is significantly different than what they recalled months later. Since nearly all research on learning in museums is conducted in the museums, this is a potentially cautionary finding. At the very least, it suggests a division between short-term and long-term results. We might also ask what term is most useful: Three months? Six months? Six years? All we know now is that outcomes change over time, unpredictably.

Continuing research might create a typology of factors explaining: why visitors select specific exhibits; what range of outcomes is likely in a specific exhibit; and how museum professionals can design with these questions in mind. This study also raises questions about the role of context. We chose interactives representative of types one sees in museums and science centers. We did not match "pairs" of exhibits across the two venues. There were marked differences between visitors' perceptions of interactives in museums and science centers. It may be possible to continue this investigation into the effects of context.

This study is the beginning of a process to investigate the role of museum and science center interactives in the visitor experience. As we build on this approach in the future, we believe that we will be able to develop a more meaningful and accurate understanding of the educational benefits of specific exhibit interactives and the overall role that interactivity plays in facilitating the museum experiences of the visiting public.

\section{NOTE}

1. These studies offer a useful guide to interactivity: Adams, Moreno, Polk, and Buck 2003; Allen 2002; Allen and Gutwill 2003; Anderson, Lucas, Ginns, and Dierking 2000; Borun, Chambers, and Cleghorn 1996; Dierking and Falk 1998; Dierking, Luke, and Büchner 2002; Feher and Rice 1985; Hein 1989; Rennie and McClafferty 1996; Stocklmayer and Gilbert 2001.

\section{ACKNOWLEDGMENTS}

We would like to thank the staff of the Powerhouse Museum and Scitech Discovery Centre for their cooperation and support. A special thanks to Leanne Atkins, Paul Nichols, Leonard Wee and Joe Heimlich.

\section{REFERENCES}

Adams, M., C. Moreno, M. Polk, and L. Buck. 2003. The dilemma of interactive art museum spaces. Art Education 56 (5): 42-52. 
Adelman, L. M., J. H. Falk, and S. James. 2000. Assessing the National Aquarium in Baltimore's impact on visitors' conservation knowledge, attitudes and behaviors. Curator: The Museum Journal 43 (1): 33-62.

Allen, S. 2002. Studying visitor meaning-making at exhibits. Session presented at the annual meeting of the Association of Science-Technology Centers (ASTC), Charlotte, NC.

Allen, S. and J. Gutwill. 2003. Assessing techniques for facilitating meaning-making by science museum visitors. Paper presented at the annual meeting of the American Educational Research Association, Chicago, April.

Anderson, D. 1999. Understanding the impact of post-visit activities on students' knowledge construction of electricity and magnetism as a result of a visit to an interactive science centre. Unpublished doctoral dissertation, Queensland University of Technology. Brisbane, Australia.

Anderson, D., K. B. Lucas, I. S. Ginns, and L. D. Dierking. 2000. Development of knowledge about electricity and magnetism during a visit to a science museum and related post-visit activities. Science Education 84 (5): 658-79.

Ansbacher, T. 2003. What are we learning? Outcomes of the museum experience. Informal Learning Review 53 (March-April).

Bernard, H. R., and G. W. Ryan. 1998. Text analysis: Qualitative and quantitative measures. In Handbook of Methods in Cultural Anthropology, H. R. Bernard, ed. Walnut Creek, CA: Altamira Press.

Bielick, S. and D. Karns. 1998. Still thinking about thinking: A 1997 telephone follow-up study of visitors to the Think Tank exhibition at the National Zoological Park. Washington DC: Smithsonian Institution, Institutional Studies Office.

Borun, M., M. Chambers, and A. Cleghorn. 1996. Families are learning in science museums. Curator: The Museum Journal 39 (2): 15-20.

Bransford, J. D., A. L. Brown, and R. Cocking. 1999. How People Learn: Brain, Mind, Experience and School. Washington DC: National Research Council. Damasio, A. R. 1994. Descartes' Error: Emotion, Reasons, and the Human Brain. New York: Avon Books. 
Dierking, L. D., J. J. Luke, and K. S. Büchner. 2002. Science and technology centers—rich resources for free-choice science and technology learning. International Journal of Technology Management on Science and Technology Centres 25 (5): 56-65.

Dierking, L. D., M. Cohen Jones, M. Wadman, J. H. Falk, M. Storksdieck, and K. Ellenbogen. 2002. Broadening our notions of the impact of free-choice learning experiences. Informal Learning Review 55 (July-August).

Dierking, L. D. and J. H. Falk. 1998. Audiences and accessibility. In The Virtual and Real: Uses of Multimedia in Museums, S. Thomas and A. Mintz, eds., 57-72. Washington DC: American Association of Museums.

Ellenbogen, K. M. 2002. Museums in family life: An ethnographic case study. In Learning conversations in museums, G. Leinhardt, K. Crowley, and K. Knutson, eds., 81-101. Mahwah, NJ: Lawrence Erlbaum Associates.

- 2003. From dioramas to the dinner table: An ethnographic case study of the role of science museums in family life. Unpublished doctoral dissertation, Vanderbilt University.

Edelman, G. 1987. Neural Darwinism: The theory of group selection. New York: Basic Books.

Falk, J. H. 1997. Recent advances in the neurosciences: Implications for visitor studies. In Visitor Studies: Theory, Research and Practice, Vol. 9, M. Wells and R. Loomis, eds., 227-38. Jacksonville, AL: Visitor Studies Association.

- 2003. Personal meaning mapping. In Museums and Creativity: A Study into the Role of Museums in Design Education, G. Caban, C. Scott, J. Falk and L. Dierking, eds., 10-18. Sydney, Australia: Powerhouse Publishing.

Falk, J. H., T. Moussouri, and D. Coulson. 1998. The effect of visitors' agendas on museum learning. Curator: The Museum Journal 41 (4): 107-20.

Falk, J. H. and L. D. Dierking. 1992 The Museum Experience. Washington DC: Whalesback Books.

- 2000. Learning from Museums: Visitor Experiences and the Making of Meaning. Walnut Creek, CA: AltaMira Press.

Feher, E. and K. Rice. 1988. Shadows and anti-images: Children's conceptions of light and vision, II. Science Education 72(5):637-49.

Hein, G.E. 1998. Learning in the Museum. London: Routledge. 
Leinhardt, G., K. Crowley, and K. Knutson. 2002. Learning Conversations in Museums. Mahwah, NJ: Lawrence Erlbaum Associates.

Luke, J. L., L.D. Dierking, and J. H. Falk. 2001. The Children’s Museum of Indianapolis Family Learning Initiative: Phase I baseline report. Technical report. Annapolis, MD: Institute for Learning Innovation.

Luke, J. L., L. Dierking, M. Cohen Jones, and M. Wadman. 2002. The Children’s Museum of Indianapolis Family Learning Initiative: Phase II report. Technical report. Annapolis, MD: Institute for Learning Innovation.

Medved, M. I. 1998. Remembering exhibits at museums of art, science and sport. Unpublished doctoral thesis, University of Toronto.

Nader, K. 2003. Memory traces unbound. Trends in Neurosciences 28 (2): 65-72.

Paris, S. G., ed. 2002. Perspectives on object-centered learning in museums. Mahwah, NJ: Lawrence Erlbaum Associates.

Piaget, J. 1952. The origins of intelligence in children. M. Cook, trans. New York: International Universities Press.

Rennie, L. and T. P. McClafferty. 1996. Science centres and science learning. Studies in Science Education 22: 53-98.

Schacter, D. L. 1999. The seven sins of memory: Insights from psychology and cognitive neuroscience. American Psychologist 54: 182-203.

Serrell, B. 1998. Paying Attention: Visitors and Museum Exhibitions. Washington DC: American Association of Museums.

Stevenson, J. 1991. The long term impact of interactive exhibits. International Journal of Science Education 13: 521-31.

Stocklmayer, S. M. and J. K. Gilbert. 2001. New experiences and old knowledge: Towards a model for the personal awareness of science and technology. Paper presented at the National Association for Research in Science Teaching Annual Meeting, St. Louis, MS.

Sylwester, R. 1995. In celebration of neurons. Alexandria, VA: Association for Supervision and Curriculum Development. 


\section{Appendix A-In-Museum Interview Protocol}

\section{GREETING}

Good morning/afternoon. We are trying to learn more about how our visitors use and think about our exhibits here today and wondered if you might help us. If you are agreeable, we would like to offer you this lovely book/free pass in appreciation for your time.

Participation in the study will take an hour of your time today, but your family and friends are welcome to accompany you for part of it, although we will be conducting two short interviews with you alone.

Thank you—please follow me.

\section{PRE-INTERVIEW}

[Interviewer: show respondent a sheet with the word "museum"/"science center" in the middle.] Question: What comes to mind when you see the word "museum” [science center]? Write your thoughts down in black pen.

Probe: Now, let's have a look at what you've written. Could you explain/elaborate a bit more about what you are thinking here, what does $X$ have to do with "museums" [science centers] ... and here ... and here ... [Interviewer writes responses in red.]

Probe: Let me ask you before you explore this exhibition—how would you rate your interest in ecological and environmental issues/physics and chemistry [science] on a scale of low/moderate/high? How would you rate your knowledge of ecological and environmental issues/physics and chemistry [science] on a scale of low/moderate/high? [Interviewer: explore a little further if moderate or high response is given.]

\section{EXHIBITION VISIT}

Direction: Now, I would like to ask you to take some time to explore this exhibition. Take as long as you want to look around this exhibition [pointing out the boundaries of the exhibition]; and at some point in your visit I'd like you to use these two specific particular exhibits [pointing out the specific interactives selected for this subject].

When you finish, I may want to chat with you further. Enjoy.

\section{OBSERVATION}

Unobtrusively observe the visitor and make notes on what they do in general and with the target interactives in particular. 
Observation: Interviewer: observe respondent in relation to:

- content-curiosity, attention, duration of engagement

- social-engagement with others (own group/other visitors) in relation to exhibits, enjoyment/frustration

- museum literacy-selectivity, range of selection

\section{POST-INTERVIEW}

Prompt: Now—could you please look at your sheet again? As the result of the exhibition visit, is there anything that you would change/add/delete? Write in blue.

Question: Could you explain/elaborate a bit more about what you were thinking here, what does $X$ that you've added have to do with museums/science centers? . . . and here ... and here? [Interviewer: write what the visitor says on the same piece of paper; use back if necessary. Interviewer writes in green.]

Question: Tell me what you thought of the exhibition I invited you to visit. Was there anything that stood out as particularly interesting or thought provoking? Any parts you particularly liked or disliked?

Question: Thinking now of the two exhibits that I suggested you use, what was the most significant part of the experience for you (e.g., Gridlock, then Bigfoot, or Firebrigade, then Fireworks).

Question: If you were to describe this exhibit to friends or family, how would you describe it? Question: As the result of using this exhibit, do you think about ecological and environmental issues/physics and chemistry [science] any differently? If so, in what ways? If not, why not?

Prompt: [Interviewer: show sheet with four images of visitors using interactives.] Here are some pictures of visitors using exhibits in this museum/science center.

Question: What role do you think exhibits like these play in the museum/science center experience?

[Interviewer: Probe respondent's replies. Ask them to clarify, elaborate, give an example. The respondent's comments might be synergistic with the concepts outlined below, but may (equally) be something we have not thought of.]
a) Content

Principles, processes and knowledge learned; 
Attitudes, values, beliefs changes/challenged/confirmed;

Awareness extended;

Curiosity stimulated.

b) Social experience

Awareness of new behaviors/learning/knowledge outcomes experienced by accompanying others;

Enjoyment experienced;

Collaborative learning engaged in.

c) Museum literacy

Awareness of museums as places:

— which offer more information on a topic;

—which stimulate curiosity;

—which stimulate wonder;

—where one can have positive social interactions;

—which offer different ways to learn.

Use of museums:

—-knowledgeable selectivity of experiences;

— knowledge of the range of experiences available.

\section{QUESTIONNAIRE}

One more final thing, would you be willing to fill in this brief questionnaire which gives us some information about who you are and what previous experiences you've had with museums/science centers? [Include a question at end about possibly contacting them again in the future and if they would be willing to give us permission to do so, and if so, a way to contact them.]

Thank you so much for taking the time with us today. I hope you enjoy the rest of your visit.

[Interviewer: if all else fails, see if you can get their name, address and telephone number.]

\section{Appendix B-Follow-up Telephone Interview Protocol}


Much of what an individual or family "learns" in a museum or science center only becomes apparent weeks, months, or even years after the experience, and then only in relation to the individual's or family's own personal construction of knowledge. To better understand the impact of the museum/science center experience, we will conduct follow-up telephone interviews with the set of individuals who provided contact information during their interview at the museum/science center. Although we will try, it is unlikely we will be able to reach everyone on the list.

How to initiate the follow-up phone interview-Before calling the selected individual, you will want to familiarize yourself with their experience at the museum/science center by reviewing their entry and exit interview and Personal Meaning Mapping responses. The goal is to get a sense of who this person is, the nature of their experience, and their perspective on the museum/science center and interactives both prior and subsequent to their experience. The telephone interview will essentially follow-up on their museum/science center visit, so it is necessary to be as familiar with their initial experience as possible.

Call the adult, introduce yourself, and remind the adult that he/she gave their name for participation in a follow-up study about their experience at the Powerhouse Museum/ Science Center. You may want to use some variation of the following script:

Hi, my name is__. I work with (The Powerhouse Museum/Science Center). A few months ago you participated in an interview about your museum/science center experience. At that time, you agreed to be part of a follow-up telephone interview a couple of months after your visit. Do you have a few minutes to talk to me or can we arrange for a convenient time for me to call you back? The interview should take approximately 20 minutes but you are free to cut it short if you need to go! Your feedback will really help us better understand the nature of people's experiences at the museum/science center.

If the individual wishes to be called back at a later time, schedule a time and call them back at that date and time. If the individual does not wish to be called back, thank them for their time.

\section{[... Editor's note: Call-back procedures are not included here.... ]}

Conducting the follow-up phone interviews - In order to establish an effective protocol for collecting follow-up data from visitors, we will conduct a handful of pilot interviews (approximately five or so) that test the effectiveness of the questions as well as the length of the interview. In our opinion it will likely be necessary to separate the follow-up phone interview into two protocols: the first protocol's questions (Protocol I, below) would be focused on what the respondent now thinks of a museum/science center, and the second protocol's questions (Protocol II, below) would be focused on what the respondent says about the outcomes of their experience with the two specific interactives they saw, assessing the long-term impact of the museum interactives on their learning. The pilot interviews, however, should be conducted using 
the full protocol (both Protocol I and Protocol II, below). If the full interview proves to be unwieldy (in terms of length), use the split protocols.

At the start of the interview it will be important to "set the stage" for the adult, reminding them that someone talked to them when they were at the museum/science center a few months ago (January/February). Maybe even remind them of what they said was the reason for them coming to the Powerhouse/SciTech that day (as indicated on their data sheet) and what specific exhibits/areas we asked them to visit (e.g., Ecologic, the Thongaphone exhibit). You may need to use some appropriate conversational cues to build a rapport with the adult. Do whatever it takes to set the stage in a conversational, easy-going fashion in order to take the person "back in time" to the day of their visit. This will be particularly important when describing the interactives each person visited at the museum/science center (Protocol II).

Conducting the phone interview is similar to conducting the face-to-face interviews in the museum — all the same rules apply. Over the phone there are a few more "good interviewing skills” to keep in mind. Since you aren't able to maintain visual contact with the adult, it's often useful to affirm what they are saying, and let them know you are listening, by periodically saying things such as "I see” or "Umhmm” or "Right.” It is also important to maintain the person's attention and keep them focused. This will be particularly important when you're discussing the learning dimensions in the interview (Protocol II).

Use both Protocol I and Protocol II when pilot testing the interview.

\section{Protocol I. Perspectives on a museum/science center:}

When you were at the Powerhouse Museum/Science Center a few months ago, we spoke with you about your ideas/thoughts of a (museum/science center). If you remember, we gave you a sheet of paper with the word(s) museum/science center. Do you remember that exercise? [Wait for response]

You used words like and and to describe a (museum/science center). I'd like to do a similar exercise over the phone, but I'm interested in finding out how you are thinking about museums/science centers now. What comes to mind right now when you hear the word "museum"/"science center"?

If necessary, remind them again of some of the things they said before and ask: Would you like to add/delete/change anything from your original thoughts?

[If the respondent did not mention any of the following categories:] Probe:

a. In your opinion, who goes to a (museum/science center)? Who is the (museum/ science center) experience designed for?

b. What sort of atmosphere do you associate with a (museum/science center)? 
c. What sorts of displays or exhibits do you expect to find at a (museum/science center)?

d. Do you see the (museum/science center) as a place to learn? If so, can you describe learning for me at the (museum/science center)?

\section{Protocol II. Outcomes:}

We spoke with you at the (Powerhouse Museum/Science Center) and asked you to utilize and then comment on two interactives, the: and _. If you remember, interactive was [Describe interactives simply]. Do you remember these interactives?

[Wait for response.]

Let's start by talking about the interactive. Now, a few months after your visit, what would you say you got out of that experience in particular? Has there been anything you have done or thought of as a result of that particular experience? In the last few months, have you had an opportunity to build on your experience at that interactive?

[Repeat for the second interactive.]

Great. Now I'm going to quickly go through a list of eight learning dimensions, and I'm going to ask you to rate the extent to which you learned during your experience with those particular interactives. Please use a 1-10 scale where 1 means you feel that you had absolutely no benefit or change to you in this area as a consequence of interacting with that exhibit and 10 means you feel that you experienced considerable benefit or change to you in this area as consequence of interacting with that exhibit. How much did you get out of your experience with the interactive in terms of:

a. Knowledge? [Repeat, on a scale of 1-10, 1 being no change or enhancement to your knowledge and 10 being considerable change or enhancement to your knowledge and understanding.]

b. Skills? [How would you rate a change in your skills on a scale of 1-10?]

c. Interests? [Repeat procedure if necessary, they should be catching on by now.]

d. Awareness?

e. Values?

f. An understanding of museums?

g. Social skills/relationship building?

h. Creativity? 
[If the respondent rates one of the learning dimensions higher/equal to/greater than a 7:] Probe: That is interesting. It seems like you got a lot out of the interactive in that respect.

Can you give me an example of how that happened for you? Why did you rate it that way?

[Repeat for the second interactive.]

Perhaps the most important aspect of any interview, be it over the phone or face-to-face, is to probe people's initial responses. Please make sure you follow-up on people's replies by asking further clarification questions. In this way, we will be sure to end up with a rich, meaningful data set!

Ending the follow-up phone interview - At the end of the interview, thank the respondent for their time, and let the adult know that his/her feedback will be extremely valuable as the museum/science center strives to provide quality experiences for people. At this time, you may also want to ask respondents if they have any questions of their own, before ending the interview. 